[Agr. Biol. Ghem., Vol. 25, No. 2, p. 141 143, 1961]

\title{
Studies on Phenolic Lactones.
}

\section{Part VI. Synergistic Activities of Phenolic Lactones.}

\author{
By Kyôhei Yamashita and Masanao Matsui \\ Faculty of Agriculture, University of Tokyo \\ Received August 24, 1960
}

\begin{abstract}
The synergistic action of phenolic lactones on allethrin and pyrethrin were investigated from the mortality of synergized pyrethroids against rice-weevil by petri-dish method.

In the series of $a$-benzylidene- $\gamma$-butyrolactones, $( \pm)$ hibalactone and $a$-piperonylidenebutyrolactone were appreciably synergistic on allethrin although less effective than piperonyl butoxide. ( \pm ) Hinokinin, 2-piperonylidene-3-piperonyl-1,4-butanediol also showed week activation, but $a$-benzylidene-, $a$-anisylidene-, $a$-veratrylidene-butyrolactone, $a$-piperonylidene$\boldsymbol{a}^{\prime}$-piperonyl-tetrahydrofuran, $\boldsymbol{\alpha}$-trimethoxybenzylidene- $\beta$-trimethoxybenzyl-butyrolactone were not synergistic on the insecticidal action.

In the series of synergized pyrethrin, ( \pm ) hibalactone and a-piperonylidene-butyrolactone showed week synergism but the other test compounds showed no appreciable synergism.
\end{abstract}

Pyrethrin and allethrin are activated by various synergists such as sesamin ${ }^{1)}$, asarinin and sesamoline ${ }^{2)}$. H. Matsubara ${ }^{3)}$ found that hibalactone has strong synergistic action against house-flies and mosquito larvae. By many investigators it was found that the combination of allethrin with 3,4-methylenedioxyphenyl synergists were, in general, less effective than the similar combination of pyrethrins but the results obtained by Matsubara did not agree with these informations.

To find the relation between chemical structure and synergistic action of hibalactone and related compounds, the authors prepared some of phenolic lactones and related compounds and examined the synergistic action of these compounds.

As a simple screening method the authors used rice-weevil as the test insecticides and the effectiveness were examined by petri-dish

1) H.L. Haller, E.R. MacGovran, L.D. Goodhue, W.N. Sullivan, J. Org. Chem., 7, 183 (1942).

2) M. Bcroza, J. Am. Oil Chemists' Soc., 31, 302 (1954).

3) H. Matsubara, This Journal, 21, 132 (1957). method. Pyrethroid-synergists ratio in synergized solutions were $1: 10$. In the test on the mortality effectiveness of synergized allethrin solutions against rice-weevil ( \pm ) hibalactone (I) , $\quad \alpha$-piperonylidene-butyrolactone (II, $\mathrm{R}, \mathrm{R}^{\prime}=\mathrm{CH}_{2} \mathrm{O}_{2}$ ) were appreciably synergistic although less effective than piperonyl butoxide. ( \pm ) Hinokinin (III), 2-piperonylidene3-piperonyl-1,4-butanediol (IV) also showed week activation but $\alpha$-benzylidene-butyrolactone (II, $\left.\quad \mathrm{R}=\mathrm{R}^{\prime}=\mathrm{H}\right), \quad \alpha$-anisylidene-butyrolactone (II, $\mathrm{R}=\mathrm{H}, \mathrm{R}^{\prime}=\mathrm{CH}_{3} \mathrm{O}$ ), $\alpha$-veratrylidenebutyrolactone (II, $\left.\mathrm{R}=\mathrm{R}^{\prime}=\mathrm{CH}_{3} \mathrm{O}\right), \quad \alpha$-piperonylidene- $\alpha^{\prime}$-piperonyl-tetrahydrofuran (V) and $\alpha$-trimethoxybenzylidene- $\beta$-trimethoxybenzyl-butyrolactone (VI) were not synergistic or disturbed the insecticidal action. The degree of synergism calculated from the lethal concentration by the probit method developed by Bliss are: $( \pm)$ hibalactone 3.06 , ( \pm ) hinokinin 1.43, $\alpha$-piperonylidenebutyrolactone 2.37, piperonyl butoxide 10.0. In the case of synergized pyrethrin, pipero- 
<smiles>CC(Cc1ccc2c(c1)OCO2)CC(O)OCCO</smiles>

( I )<smiles>OC/C(=C/c1ccc2c(c1)OCO2)Cc1ccc2c(c1)OCO2</smiles>

( IV)

nyl butoxide activated its effectiveness six to seven times and $( \pm)$ hibalactone, $( \pm)$ hinokinin and $\alpha$-piperonylidene-butyrolactone showed some synergistic action qualitatively but the other test compounds did not shown appreciable synergism.

From these results it seems that such synergistic activities of hibalactone or $\alpha$-piperonylidene-butyrolactone with allethrin are caused not only by the possession of $\gamma$-lactone ring but by the presence of 3,4-methylenedioxyphenyl group.

\section{EXPERIMENTAL}

\section{Tost Sample}

The standard pyrethroids employed in the experiment were $15 \%$ solution of pyrethrin prepared by Nagaoka Insecticides Co. Ltd., and pynamin containing $91 \%$ of allethrin prepared by Sumitomo Chemical Co. Ltd..

Test compounds were synthesized by general methods: $\alpha$-benzylidenebutyrolactone, m.p. 115 $117^{\circ} \mathrm{C}^{4,5)}, \alpha$-anisylidene-butyrolactone, m.p. $125 \sim$ $127^{\circ} \mathrm{C}^{4,5)}, \alpha$-veratrylidene-butyrolactone, m.p. 115 $117^{\circ} \mathrm{C}^{4,5)}, \alpha$-piperonylidene-butyrolactone, m.p. $177 \sim$ $178^{\circ} \mathrm{C}^{4,5)}, \alpha$-trimethoxybenzylidene- $\beta$-trimethoxybenzyl-butyrolactone, m.p. $90 \sim 91^{\circ} \mathrm{C}^{4}$ ), (士) hibalactone, m.p. $\left.154 \sim 155^{\circ} \mathrm{C}^{6}\right)$, (士) hinokinin, m.p. $109^{\circ} \mathrm{C}^{7)}, 2-$ piperonylidene-3-piperonyl-1,4-butanediol, m.p. 115 $\sim 117^{\circ} \mathrm{C}^{6)}$.

4) K. Yamashita and M. Matsui, This Journal, 24, 711 (1960).

5) H. Zimmer and J. Rothe, J. Org. Chem., 24, 28 (1959).

6) K. Yamashita and M. Matsui, This Journal, 24, 160 (1960).

7) K. Yamashita and M. Matsui, ibid., 22, 273 (1958).<smiles>[R]c1cc(/C=C2\[CH]COOC2)ccc1I</smiles>

( II )<smiles>CCC(CC1=C2C=CC(=CO2)C=C1)Cc1cccc(OC)c1</smiles><smiles>COc1cc(CCC(=O)Cc2cc(OC)c(OC)c(OC)c2)cc(OC)c1OC</smiles>

( VI)

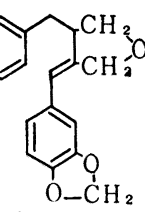

$a$-Piperonylidene- $\alpha^{\prime}$-piperonyl-tetrahydrofuran was prepared by heating the corresponding glycol with potassium hydrogen sulfate at $180^{\circ} \mathrm{C}$ by the similar method in the synthesis of 3,4-bis- (3,4-dimethoxybenzyl) -tetrahydrofuran ${ }^{8)}$ and the crude product was examined.

Test insects were rice-weevil, Calandra oryzae L., 40 50 days grown after hatching.

\section{Method}

Pyrethroids and synergists were dissolved in acetone. Pyrethroids synergists ratio in synergized solution were $1: 10$.

One milliliter of acetone solution were poured into petri-dish of $15 \mathrm{~cm}$ diameter and thin film were made by the evaporation of solvent. Twenty individuals of test insecticides were placed in petri-dish and put on the cover. After incubation for 24 hours at $30^{\circ} \mathrm{C}$, the contents of each dishes were poured out on filter paper and allow to stand for an hour. The dead individuals remaining on the filter paper were counted and the total mortality were calculated.

In the same test compounds, four concentrations were selected and in each concentration sixty to eighty individuals were used.

\section{RESULTS}

The total mortality after 24 hours and the concentration of acetone solution were shown in Table I and II.

From the results shown in Table I, the degree of synergism of these compounds were

8) A.W. Schrecker and J.L. Hartwell, J. Am. Chem. Soc., 77, 432 (1955), 
TABLE I. CONCENTRATION (ppm)-MORTALITY (\%) OF RICE-WEEVIL FOR SYNERGIZED Allethrin Solution With Phenolic Lactones.

Test compounds

- (control)

piperonyl butoxide

$( \pm)$ hibalactone

$\alpha$-piperonylidene-butyrolactone

2-piperonylidene-3-piperonyl-1, 4-butanediol

$( \pm)$ hinokinin

$\alpha$-piperonylidene- $\alpha$ '-piperonyltetrahydrofuran

$\alpha$-trimethoxybenzylidene- $\beta$-trimethoxybenzyl-butyrolactone

$\alpha$-anisylidene-butyrolactone

$\alpha$-veratrylidene-butyrolactone

$\alpha$-benzylidene-butyrolactone

$\begin{array}{lcccccc}200 & 100 & 50 & 25 & 12.5 & 6.25 & 3.125 \\ 93.3 & 73.3 & 43.3 & 21.7 & & & \\ & 100 & 100 & 93.3 & 81.7 & 55.0 & 31.7 \\ 98.3 & 93.3 & 86.7 & 60.0 & & & \\ 98.3 & 93.3 & 73.3 & 55.0 & & & \\ 96.7 & 93.3 & 71.7 & 41.7 & & & \\ 95.0 & 80.0 & 58.3 & 36.7 & & & \\ & 35.0 & & 3.3 & & & \\ & 6.7 & 6.7 & 5.0 & & & \\ & & 21.3 & & & & \\ & & 18.3 & & & \end{array}$

TABLE II. CONCENTRATION (ppm)-MORTAlity (\%) OF RICE-WEEVIL FOR SYNERgIZED Pyrethrin SOLUTION WITH PHENOLIC LACTONES

concentration of pyrethrin (ppm)

Test compounds

- (control)

piperonyl butoxide

$( \pm)$ hibalactone

$\alpha$-piperonylidene-butyrolactone

(士) hinokinin

$\boldsymbol{\alpha}$-anisylidene-butyrolactone

$\alpha$-benzylidene-butyrolactone

$\alpha$-veratrylidene-butyrolactone

2-piperonylidene-3-piperonyl-1, 4-butanediol

$\boldsymbol{\alpha}$-piperonylidene- $\boldsymbol{\alpha}$ '-piperonyltetrahydrofuran

$\alpha$-trimethoxybenzylidene- $\beta$-trimethoxybenzyl-butyrolactone

$\begin{array}{lccrrr}100 & 50 & 25 & 12.5 & 6.25 & 3.125 \\ 93.3 & 43.3 & 18.0 & 5.0 & & \\ & 100 & 100 & 85.0 & 60.0 & 30.0 \\ & 96.7 & 73.3 & 20.0 & 13.3 & \\ & 85.0 & 48.3 & 33.3 & 13.3 & \\ 75.0 & 50.0 & 30.0 & 20.0 & \\ 90.0 & 16.7 & 5.0 & & \\ 81.3 & 20.0 & 10.0 & & \\ 88.3 & & 6.7 & & \\ 51.7 & & 13.3 & & \\ 88.3 & & 3.3 & & \\ 10.0 & 5.0 & 3.3 & & \end{array}$

synergism were: piperonyl butoxide 10.0, ( \pm ) hibalactone 3.06, $\alpha$-piperonylidene-butyrolactone 2.87, 2-piperonylidene-3-piperonyl-1,4butanediol 2.00, $( \pm)$ hinokinin 1.43 .

Acknowledgement The authors wish to express their thanks to Mr. H. Sugawara and Mr. T. Kaneko of Agricultural Chemicals Inspection Station for their kind guidance and cooperation. 